\title{
Rekreasyon ve Turizm Araştırmalarında Fırsatçılık ve Düşündürdükleri
}

\author{
Özkan TÜTÜNCÜ \\ Dokuz Eylül Üniversitesi \\ Necat Hepkon Spor Bilimleri Fakültesi
}

\section{GiRiş}

Son yıllarda ülkemizde turizm alanında yayın yapan birçok yeni elektronik dergiyle karşılaşmaktayız. Dergi sayısının akademik teşvik sisteminden sonra daha hızlı bir şekilde arttığı gözlemlenmektedir. Akademik teşvikte editör olmanın puan getirmesi, çok sayıda kalitesi şüpheli derginin oluşmasını beraberinde getirmiş ve getirmeye de devam etmektedir. Dergi sayısındaki artışa bağlı olarak bu dergilerin yayın ihtiyacı ve yine akademik teşvikte yayınların puan getirmesinden dolayı, yayın sayılarında önemli bir artış söz konusudur. Teşvik sistemi, üstüne COVID-19 pandemisi ve daha birçok başka nedenden dolayı ortaya çıkan yeni durum, bir başka bakış açısıyla yeni fırsatları (?) da beraberinde getirmiştir.

Makalenin yazarı olarak neredeyse her gün bir COVID-19 çalışmasına destek vermem için eposta almaktayım. Muhtemelen benzer e-postalar ile sizler de karşılaşmaktasınız. Gönderilen turizm, rekreasyon ve boş zaman ile ilgili olan çalışmaların anket ve soru formları incelendiğinde, bu çalışmaların önemli araştırma tasarımı ve yöntem hatalarına sahip olduğunu her iyi eğitimli araştırmacı anlar. Aslında COVID-19 öncesinde elektronik yayınlanan dergi sayısındaki ve bunların içini doldurmaya çalışan makalelerdeki artış, nitelik sorununu gündeme getirmekteydi. $\mathrm{Bu}$ çalışmanın konusunun belirlenmesine her ne kadar COVID-19 bazında gönderilen veya yapılan araştırmalar neden olsa da COVID-19' dan öncesi alanımızda yapılan araştırmalardaki temel sorunların devam ediyor olması da ana etmendir. Öte yandan alanımızda yapılan her araştırma makalesi için burada ele alınan sorunların geçerli olduğunu savunmak olası değildir. Bununla birlikte titizlikle hazırlanmamış, halen yürütülmekte olan ve yayınlanan araştırmaların temel sorunları, burada belirli başlıklar altında ele alınmaya çalışılacaktır.

\section{ARAŞTIRMA SÜRECINDEKI SORUNLAR}

Pandemi süreci turizm ve rekreasyon alanında araştırma yapan bazı kişiler için "Bu süreci fırsata çevirebilir miyiz?" sorusunu da beraberinde getirdi ve hızla bu konuda çalışmalar yapılmaya başlandı. Aslında hızlı bir şekilde çalışmalara başlanılması isteğinin hiçbir sakıncası olmadığ gibi faydası olduğu da savunulabilir. Bununla birlikte fırsatçı yaklaşımın sonucu olarak ortaya çıkacak sağlıklı hazırlanmamış araştırmaların, yağmacı dergiler için bir potansiyel yaratabileceği düşünülmektedir. Bu aşamada farklı başlıklar altında ele alınması gereken değişik sorunlarla karşılaşılmaktadır.

\section{Araştırma Sorusunun Belirlenmesi ve Kuramsal Yapı ile İlgili Sorunlar}

Pandemi süreciyle birlikte "Hadi Hocam COVID-19 ve turizm-rekreasyon ilişkisi ile ilgili bir çalısma yapalım." diyen meslektaşlarım ile sıklıkla karşılaşmaktayım. Böyle bir yaklaşıma verdiğim ilk yanit "Elbette olabilir, bunu bir proje önerisi olarak hazırlayıp sunabilir misiniz?" olmaktadır. Bu yanıt işi zora sürme gibi gözükse de aslında yapılacak her önemli araştırma için araştırma projesi önerisi hazırlanma gerekliliğinin, ülkemizde göz ardı edildiğinin de bir göstergesidir. Hazırlanacak iyi bir araştırma projesi önerisi, hem kaynak bulmak ve bunları iyi kullanmak açısından hem de araş- 
tırmanın daha sağlıklı gitmesi açısından önem taşımaktadır (Tütüncü 2000). Buradaki kaynak sadece finansal açıdan ele alınmamalı, sağlayaca$\breve{g} 1$ zaman ve ekibin motivasyon kazanımları olarak da değerlendirmelidir. Ülkemizde turizm ve rekreasyon alanında bir çalışmaya başlamadan önce araştırma projesi önerisi hazırlayan var mı merak etmekle birlikte, yurtdışındaki ciddi üniversitelerde bir araştırma yapmak için -A.B.D.'de altı farklı üniversitede yaptığım araştırmalardan hareketle- proje önerisi yazmanız gerekmektedir. Fırsatları değerlendirmek adına bir araştırma önerisi hazırlanmadan doğrudan araştırmaya geçilmesi, burada birazdan ele alınacak birçok sorunu da beraberinde getirmektedir.

Araştırmacıların tam olarak neyi araştıracaklarının net olmaması, ana sorunlardan birinin oluşturmaktadır. Araştırmayı kurgularken, amacını tam olarak belirlememek ve bu çalışma ne işe yarayacak sorusunun yanitının verilememesi bu kapsamda ele alınabilir. Bunun en büyük nedeni araştırmacıların çalışmanın nedenlerini oluşturan arka plandaki olgulardan, kuramlardan ve/ veya pratiklerden uzak olmasıdır. Bundan önce yaşanmış krizlere bakmadan, özellikle pandemi ile ilgili süreçlerin algılanması zordur. Bu nedenle öncelikle geçmişte yaşanmış benzer krizlerin turizm ve rekreasyon alanı ile kısıtlamadan diğer bir ifade ile farklı bilim alanlarındaki ve disiplinlerdeki etkileri ile birlikte incelenmesi ve nelerin, hangi hedef kitle üzerinde, nasıl araştırıldığının kuramsal temelleriyle birlikte ele alınması gerekmektedir. Böylelikle araştırma sorusu net bir şekilde ortaya konulabilecek ve çalışmanın nitel veya nicel olmasına göre bu sorular çeşitlendirilip, hipotezler ortaya konulabilecektir.

Son dönemde tarafıma hakem olarak değerlendirmem için gelen araştırmaların büyük çoğunluğunda araştırmanın temel kuramlarının araştırmacılar tarafından net olarak ortaya konulmadığı, buna bağlı olarak çalışmalarda ana araştırma sorusunun belirlenmediği, nicel çalışmalarda hipotezlerinin verilmediği, az sayıda hipotezi sunan çalışmada ise hipotezlerin gerekçelendirilmediği görülmektedir. Bundan önceki çalışmalarının neleri ortaya koyduğunu ve varsa eksiklerinden veya yapılamayanlardan yola ç1- kılarak, üretilen hipotezler gerekçelendirilmeli ve yönleri belirlenmelidir. A.B.D.' de psikoloji alanında yürütülen tez ve projelerde, araştırmacılar proje önerilerinde artık yönlü hipotezlerini belirtmeye ve araştırmaya başlamadan önce etik olarak bunları beyan etmeye yönlendirilmektedir. Bu amaçla Açık Bilim Merkezi'nin belirlediği çerçeveler kılavuz niteliğinde olup, araştırmac1ların araştırmanın sonuçlarına daha ulaşmadan evvel kendi görüşlerini ortaya koymasını teşvik etmektedir (OSFHOME 2020). Böylelikle araştırma sadece değişkenler üzerinden basit bir şekilde kurgulanamamaktadır. Ek olarak sonuçlara göre hipotezleri ele almak ve sadece test sonuçları üzerinden yorumları şekillendirecek fırsatçıl1ğın ve doğurduğu yanlışlıkların önüne geçilmesi planlanmaktadır.

\section{Ölçekler İle İlgili Sorunlar}

Ülkemizde nicel çalışmalarda karşılaşılan bir başka sorun ise yurtdışında hazırlanmış ölçeklerin ülkemize uyarlamasında ortaya çıkmaktadır. Ölçeklerin çevirisinde yeterli sayıda uzman görüşünün alınmaması, ciddi anlam bozukluklarına ve ölçeğin amacının dışına çıkmasına neden olmaktadır. Bazen araştırmacıların egosunun yüksekliğinden, bazen fırsatçllıktan, bazen diğer nedenlerden, araştırmacılar ölçek geliştirme süreçlerinde konunun uzmanlarına ulaşmamaktadırlar. Lisansüstü derslerimde öğrencilerime özellikle belirtmeme rağmen birçoğunun aynı hatayı halen sıklıkla yaptığına şahit olmaktayım. Öğrencilerim kendi çevreleri ile yetinip, yabancı dilden uyarladıkları bir ölçeği veri toplamada kullanıp test ettikten sonra karşılaştıkları manzara sonrası çıkan hasar üzerine, tarafıma gelmektedirler. Oysaki aslında işin en başında, kuram anlaşıldıktan sonra ölçek Türkçe'ye çevrilirken, uzmanlarına iş işten geçmeden başvurulmalıdır.

Sadece yeni ve ülkemizde çalışılmamış bir konu olduğunu saptayıp doğrudan anket ve ölçek üzerinden çalışmaya başlanılmasının yarattığı başka sonuçlar da bulunmaktadır. Araştırmanın kuramının ve ölçeğin hazırlanmasındaki geri planın net olarak bilinmemesi, belirli bir kültürde ortaya konmuş bir ölçeğin illa diğer kültürde çalıșılacağından hareket edilerek, çalışmanın başla- 
tılması çalışmaların sonuçlarına olumsuz etki edebilmektedir (Özen 2002). Var olan ölçeklerin yanlış veya eksik olabileceğinin göz ardı edilmesi de ayrı bir sorundur. Çalışılan özel (spesifik) alan için belki de yeni bir ölçek geliştirmeye gereksinim duyulduğunun dikkate alınması gerekmektedir. Araştırmada diğer araştırmacıların ölçeği elbette düzgün bir şekilde kullanılabilir. Burada unutulmaması gereken, özgün ölçeği geliştiren araştırmacılar ile iletişime geçilebileceğidir. $\mathrm{Bu}$ iletişimden sakınılmamalı, bunun çalışmaya yapacağı olumlu katkı dikkate alınmalıdır. Yapılacak bu görüşmeler, çalışmanın daha sağlıklı yürümesine olanak tanıyacağı gibi yeni ortak çalışmaların yapılmasına ve ölçeğin daha sağlıklı bir şekilde uyarlanmasına veya yeni bir ölçeğin geliştirilmesine de yardımcı olabilecektir.

\section{Örneklem Ile ilgili Sorunlar}

Özellikle COVID-19 süreci geçmeden hızlı bir şekilde araştırmaları tamamlama isteği, çalışmaların amacında bozulmalara neden olduğu gibi hedef kitlelerinin belirlenmesinde de sorunlar yaratmaktadır. Son dönemde sosyal medyada üyesi olduğum gruplara “... ile ilgili yaptığımız araştırmaya katılımınız ve mümkün olduğunca çevrenizdeki yakınlarınıza anketi doldurtmanız çok önemlidir." şeklinde iletiler gelmekte ve bizlerden araştırmalarını desteklememiz istenmektedir. Bu durum normal gibi gözükse de aslında bilimsel açıdan ciddi sorunlar içermektedir. Çalışmanın hedef kitlesinin ne olduğu, net değildir. Diğer bir ifade ile çalışmanın örnekleminin hangi popülasyonla ilişkili olduğu ihmal edilmektedir. İletinin gönderildiği grup ile çalışmanın konusu arasında bir ilişki olmadığı gibi ulaşılabilecek herkese anketin doldurtulması istenmektedir. Amacın sadece istatistiksel analizleri yapmak için belirli sayıda ankete ulaşılması gerekliliği olduğu ortaya çıkmakta, örneklemin hedef kitleyi temsil etmesi gerekliliği ihmal edilmektedir. Kartopu örneklemi ve kolayda örneklem adı altında yapılacak çalışmaların da bir ciddiyeti vardır. Bu tür örneklemlerde dahi hedef kitle belirlendikten sonra, araştırmacı alana hakim değilse alandaki örneklemi oluşturan belirli kişilerden yola çıkarak ve onların görüşlerini alarak, alanla ilgili ki- şileri saptayıp çalışma konusuyla ilgili veri toplamaktadır. Yoksa araştırmacının konuyla ilgili ilgisiz herkesten çabuk veri toplamak adına belirli sayıdaki anket toplamaya girişmesi ve elde ettiği verilerden analizlerini yapıp neyi temsil ettiği belli olmayan çıkarımlarda bulunması bilimsel olmayacaktır. Bazı dergilere nasıl "yağmacı" deniliyorsa, hızla çalışma yapmak adına örneklem kurallarının göz ardı edilerek "saldırgan veri toplama" ile de sadece fırsatçı yayınlar üretilebilir. Çalışmanın türüne ve amacına göre örneklemin belirlenmesi gerekliliği vardır. Bununla birlikte özellikle nicel çalışmalarda tabakalı (kümeli) tesadüfi örneklem gibi alana özgü daha sağlıklı saptamaların yapılabileceği örneklemlerin, turizm ve rekreasyon araştırmalarında yaygın kullanılmadığı görülmektedir.

Hem A.B.D. hem de ülkemizde yine daha hızlı bir şekilde veri toplamak adına öğrenciler üzerinde yapılan çalışmalara öncelik verildiği görülmektedir. Öğrenciler üzerinden elde edilen verilerle oluşturulan ölçeklerin veya diğer araştırma sonuçlarının daha sonra farklı hedef kitlelere benzer şekilde uygulanması ve aynı şekilde geçerli ve güvenilir kılınması, beraberinde eksik veya yanlış sonuçlara ulaşılmasını getirmektedir. Bu konuda özellikle A.B.D.'de son dönemde ciddi tartışmalar yapılmaktadır (Hanel ve Vione 2016). Araştırmacılar elbette çalışma alanına özel olarak öğrenciler ile çalışmalar yürütebilirler. Ancak sadece öğrencilerin görüşleri üzerinden özellikle çok değişkenli model analizleri ile topluma yönelik çıkarımlarda bulunulması sorun yaratabilmektedir.

\section{Veri Toplama Süreci İle İlgili Sorunlar}

Normal şartlarda araştırma sorusundan hareketle araştırmanın tasarlanması gerektiği bilinmekle birlikte, ülkemizde araştırma sorusundan ziyade araştırmaya baz olacak veri ve/veya bulguyu toplama sürecinin zorluk derecesi, yöntemin yanlış belirlenmesine etki edebilmektedir. Aslında nicel ve görgül olarak yürütülmesi gerektiği gayet net ve ortada olan bir araştırma konusunun, veri toplamak zahmetli olacağı için dar bir çerçevede röportaj şeklinde bir nitel çalışma olarak kurgulan- 
ması buna örnek olarak verilebilir. Araştırmacıların niceldeki veri toplama sürecinin zorluğundan kaçarak az sayıda kişi ile görüşerek, fırsatçı bir şekilde araştırma sürecini planlamaları ve nitel çalışmaları nicelden daha kolay yürütebilen çalışmalar haline sokmaları, ciddi hatalardan biridir. Nitel çalışmaları yürütmek, nicel çalışmalardan daha kolay değildir. Her iki araştırma yönteminin kendine has zorlu özellikleri bulunmaktadır. Sadece veri toplama sürecine bağlı olarak yöntem seçimini belirlemek, olumsuz sonuçlar doğurmaktadır. Nitel araştırmalardaki gömülü kuramı tam özümsemeden, bu alanda bir araştırmaya girişmek veya nicel araştırmaların sadece istatistiksel analizler üzerinden yürütülebileceğini düşünmek, araştırma sürecinin tam anlaş1madığının bir göstergesidir. Araştırma süreci ve yöntemin tam olarak anlaşılabilmesi için araştırmacıların bilim tarihi ve felsefesi konusunda temel bilgilerinin olması ve bunları araştırma süreci ile etik bir şekilde entegre edebilmesi gerekmektedir (Andersen ve Hepburn 2016).

Verilerin toplanmasında mahremiyet ve etik kuralların ihlal edilmesi, yürütülen çalışmaların geçerliği ve güvenirliği üzerinde olumsuz sonuçlar doğurmaktadır. COVID-19 pandemi süreci yüz yüze veri toplama sürecini çok zorlaştırmıştır. Öte yandan internet üzerinden toplanacak verilerin de usulüne göre toplanması gerekmektedir. Tarafıma gönderilen araştırma bağlantılarına tıklanıldığında, karşınıza doğrudan yapılacak anket çıkabilmektedir. Çalışmanın ne amaçla yapıldı$\breve{g}_{1}$, verilerin hangi ortamda nasıl saklanacağ 1 ve IP kontrolünün yapılmadığı ve katılımcılara ait verilerin araştırma amacı dişında kullanılamayacağına yönelik bir etik beyanname veya etik kurul izinlerinin alınmasına yönelik bir bildirim bulunmamaktadır. Ayrıca daha da vahimi anket formunda yer alan her hangi bir soruyu yanitlamama hakkı, katılımcıların elinden alınabilmekte, tüm soruları yanıtlaması istenebilmekte ve saldırgan veri toplamaya devam edilebilmektedir. Oysaki katılımcıların istedikleri soruyu boş bırakabilme hakları olmalıdır.

Alanımızda hem ülkemizde hem de dünyada yürütülen boylamsal (longitudinal) araştırmaların sayısı çok değildir. Araştırmacıların bir kez ya- pılan çalışmalar kadar, belirli süreç içinde aynı konuya yaklaşımın nasıl değiştiğini saptamaya olanak verecek daha detaylı araştırmalara yönelmesi, alanı zenginleştirecektir. Örneğin COVID-19 ile ilgili şu ana kadar tarafıma bu şekilde planlanmış bir çalışma ulaşmamıştır. Hem turist veya rekreasyon faaliyetini yapan kişilerin hem de bu alanda faaliyet gösteren örgütlerin sadece bugünkü durumları değil aynı zamanda bu süreçte yapılarında meydana gelen değişiklikler ele alınabilir. Ayrıca özellikle yurtdışındaki saygın dergilerde son dönemlerde çok modelli araştırmaların yayınlandığı görülmektedir. Çok modelliden kasıt, araştırmaların değişik fazlar ile ve her fazda ayrı bir değişkeni farklı örneklemler ile alarak tek bir araştırma konusu altında değerlendirmektir. Bu kapsamda bir makale içinde "Birinci Çalışma”, “İkinci Çalışma” ve "Üçüncü Çalışma" çok modelli olarak ele alınmaktadır. Bu gibi çalışmaların artması, alanımızın değerini arttırabilecektir.

\section{Araştırmacıların Uygulama Alanına Yabancı Olması ile ilgili Sorunlar}

Çalışma konularının sadece olumlu etki yaratan sonuçlara yönelik olarak ele alındığı ve egemen paradigmalar üzerinden yürütüldügü görülmektedir (Yüksel 2019). Hem turizm hem de rekreasyon faaliyetlerinin doğurabileceği olumsuz sonuçlar, yeterince araştırılmamaktadır. Bilimsel çalışmanın özünü eleştirel bakışın oluşturduğu unutulmamalıdır. Bu nedenle kar getiren konular kadar, zarara neden olan konuların da ele alınması ve tartışılması gerekmektedir. Araştırma konularının seçiminde uygulama yapılan alandaki paydaşların görüşlerinin alınmaması, ayrı bir sorunu ortaya çıkarmaktadır. Sektör ve akademi işbirliği araştırmacıların sektörden veri toplama aşamasında iyi gitmekte ancak sonrasında bir takım sorunlar doğmaktadır. Veri toplarken sektörden yardım alıp, çalışma tamamlandıktan sonra sektöre geri bildirimde bulunulmaması, birinci olarak sektöre pratik bir katkı sağlamamakta ikinci olarak da sektör akademi işbirliğini sonraki aşamalar için kısıtlamaktadır. Verileri alırken sektöre gösterilen saygının verilerin toplanması ve işlenmesinden sonra de- 
vamının gelmesi, yeni araştırmaların yapılmasına olanak tanıyabilecektir. Öte yandan sektörün içinde bulunan kişilerin görüşlerinin, dikkatli bir şekilde ele alınması gerekmektedir. Örneğin; TaTuTa (Tarım Turizm Takas) kapsamında faaliyet gösteren bir tesis sahibi ve yönetici tarafıma yeni yaşamış olduğu bir araştırma deneyimini anlattı. Köklü bir üniversitenin ilgili bölüm başkanının yaptığı anketi tesise bırakıp, bu anketi çalışanlara yaptırılmasını rica ettiğini, yöneticinin öğretim üyesinin kendisinin anketi yaptırabileceğini belirttiğinde, buna zamanın olmadığını, bir ay sonra anketleri almaya geleceğini belirterek kendi işine sahip olmadığını belirtmişti. Fakat ilginç olan tesis yöneticisi anketteki soruları tarafıma gösterdiğinde ortaya çıkmıştı. Anketin yabancı dilden Türkçe'ye devrik bir şekilde çevrilmesinin yanında, soruların birinde çalışanlara aldıkları ücretten memnuniyet düzeyleri sorgulanmaktaydı. Oysaki bu TaTuTa tesisindeki kişilerin hepsi gönüllü çalışmakta ve ücret almamaktaydılar. Araştırmacının ele aldı ̆̆ 1 konuya hâkimiyetinin az olması, yanlış veya eksik araştırmalar, sektörün akademiyle olan ilişkisine olumsuz etki etmesine neden olmaktadir.

\section{Geçerlik-Güvenirlik ve Hipotezlerle İle İlgili Sorunlar}

Şu ana kadar burada aslında ele alınan sorunların, çoğu yöntemsel eksikliklere ve yanlışlıklara değinmektedir. Nitel ve nicel araştırmalarda sağlıklı değerlendirme ve/veya karşılaştırmaların yapılabilmesi için kullanılan yöntemlerde birliğin sağlanması gerekmektedir. Bu nedenle bilimsel araştırmalarda yönteme-metodolojiye gereksinim bulunmaktadır. Herhangi bir bulgu ve/veya veri setini analiz etmeden önce bunların geçerli ve güvenilir olduğunun ortaya konulması gerekmektedir (Şener vd. 2016). Bu hem nicel hem nitel çalışmalar için gereklidir. Veri toplamada kolaya kaçmak için nitele yönelen bazı araştırmacılar, elde ettikleri bulguların geçerlik ve güvenirliğine dair hiçbir bilgiyi vermeden ve ortaya koymadan sağlıksız bir şekilde yorumlara başlamaktadır. Nicel çalışmalarda da durum farklı değildir. Geçerlik sadece bir faktör analizi sonucunu paylaşmak değildir. Yapısal geçerliğin yanında ele alınması gereken diğer görünüş-içerik ve benzeri geçerlik analizleri göz ardı edilmekte, doğrulayıcı ve açıklayıcı faktör analizlerinin hangi şartlarda nasıl kullanılacağı bilinmemekte ve bunlarda hangi testlerin ele alınacağ 1 (ML, ULS, DLS veya PA gibi) doğru bir şekilde hesaba katılmamaktadır. Araştırmacıların yaptıkları araştırmanın türüne göre geçerlik ve güvenirliğe ait bulgularını paylaştıktan sonra araştırmaları değerlendirmeye geçmeleri gerekmektedir. Araştırmacıların analizleri yaparken kullanabilecekleri birçok program bulunmaktadır. Bu programların seçiminde açık kaynak kodlu yazılımların tercih edilmesi, tarafsızlık ilkesinin ön plana çıkarılmasına yardımcı olacaktır. Son dönemde yurtdışındaki araştırmalarda açık kodlu yazılımlara yönelinmesi, sevindirici bir gelişmedir. Bu gelişmelerin ülkemizde turizm ve rekreasyon alanında da yaygınlaşmasını teşvik etmek gerekmektedir.

Nicel çalışmalarda hipotezlerin belirlenmemesi kadar, belirlenen hipotezlerin yanlış kurgulandıkları da gözlemlenmektedir. Bazı çalışmalarda evvelden yeterince test edilmiş hipotezlerin, neden tekrar test edilme gerekliliği belirtilmeden, yeniden benzer örneklemlerle test edildiği ve yine gereksiz yere yeterince kanıtlandığı görülmektedir. Hipotezlerin farklılık ve farksızlık hipotezleri olarak değerlendirilmesi gerekliliği birçok araştırmacı tarafından göz ardı edilmektedir. Bu yıl kaybettiğimiz değerli Hocamız Hasan Işın Dener'in belirttiği gibi farksızlık hipotezleri de en az farklılık hipotezleri kadar önemlidir ve sonuçlarının yorumlanmasında fayda bulunmaktadir. Hipotez testi sonucu istatistiksel olarak anlamsız çıkan bir ilişkinin, bilim hayatına anlamlı katkı yapabileceği unutulmamalıdır. Ancak her nedense sadece farklılık hipotezleri üzerinden çoğu çalışmanın yürütüldüğü görülmektedir.

Yanlış oluşturulmuş hipotezler (boş hipotezler dahil) ile bulunan ilişkilerin yorumlanması, ayrı sorunları beraberinde getirmektedir. Bu ve yukarıda bahsedilen konular üzerine meslektaşım Atila Yüksel'in (2018) çok güzel yayınlarının bulunduğunu ve özellikle "Aykırı: Araştırma Yanılsamaları"nı alanda çalışan tüm akademisyenlerin okuması gerektiğini düşünmekteyim. Turizm ve rekreasyon araştırmalarında nicel alanda yapılan çalışmaları frekansa dayalı görüş 
ve buna bağlı örneklem ve güven aralığg gibi önkoşullu istatistikler şekillendirmekle birlikte, sosyal bilimlerde belirsizliği ve öznelliği içine alan Bayes istatistiği ile çalışmaların desteklendiğ görülmektedir. Alanımızda Bayes yaklaşımlı yorumlamaların çalışmalarda ele alınması, alanımızı daha iyi ortaya koymaya yardımcı olabilir. Öte yandan değişkenler arasında çoğu zaman nedensel ve doğrusal bir ilişkinin olduğunun düşünülmesi ya da doğrusal olmayan ilişkilerin henüz alanımızdaki çalışmalarda yeterince tanımlanamaması, araştırmaların tek bir bakış açısıyla ele alınmasını ve eksik sonuçlar doğurmasını beraberinde getirmektedir. Bunların kökeninde diğer ilgili bilim dallarından destek alınmadan, sadece turizm alanındaki çalışmalar ile çalışma alanını değerlendirip, kuramsal yetkinliğe ulaşmadan ve ne nitel ne de nicel yöntemlerin tam özümsemeden çalışmaların yapılması yatmaktadır. Kervan yolda düzülür mantığı ile yanlış yapa yapa öğreniriz mantığını artık bırakmak gerekmektedir.

\section{DERGILERDEKI SORUNLAR}

Öncelikle genel bir bilgi edinmek adına Dergi Park'ta yer alan tüm dergilere ve Turizm ile Rekreasyon alanında yayın yapan dergi sayılarına bakmakta fayda vardır. İlgili alanda bulunan toplam dergi sayısı 2125 olup, yapılan taramada "turizm" anahtar kelimesini içinde bulunduran toplam 93 dergi, "rekreasyon" anahtar kelimesini içinde bulunduran ise toplam 40 dergi olduğu saptanmıştır (Dergi Park 2020). Ancak bazı dergilerin her iki kelimeyi de içerdiğini ve her iki alandan da yayın kabul ettiğini belirtmek gerekmektedir. Bununla birlikte sadece turizm alanı için dahi ülkemizde 93 akademik derginin bulundu$\breve{g} u$ ve kendini editör olarak görme eğiliminde olan fırsatçı bazı kişilerin sayısındaki artış, bu dergi sayısının daha da artacağının sinyallerini vermektedir. Her ne kadar bu çalışmanın konusu dergi editörlüğü olmasa da yayın kalitesini doğrudan etkilediği için bu alana kısa da olsa değinilecektir.

Bilindiği üzere üniversitelerin kalitelerinin belirlenmesinde yapılan yayınların niteliği ayrı bir yer tutmaktadır. Üniversite-Evrenkent kelimesi etimolojik olarak incelendiğinde, evrenselliğin bir ön koşul olduğu görülmektedir. Öte yandan ortaya çıkan bu yeni dergilerdeki editörlerinin kendi alanlarında hatırı sayılır uluslararası (evrensel) nitelikteki, ücret ödenmeden yayın yapilan dergilerde, birinci yazar ve/veya tek yazar olarak, tüm insanlığın faydalanmasına olanak verecek yabancı dilde yayınlanmış araştırmalarının olmasını beklenmek bir kalite gereğidir. Tarafıma alanında uzmanlaşmış bir derneğin yolladığı e-postada, rekreasyon alanında yayın hayatına geçmiş bir derginin tanıtımı ulaştı. Merak içinde derginin editörünün kim olduğuna ve bilim kurulunda kimlerin yer aldığına baktım. Dergi editörünü tanımadığımdan, internette basit bir araştırma yaptım ve doktorasını yeni bitirmiş genç bir akademisyen karşıma çıktı. Yabancı dilde yapılmış eserlerine baktığımda ne yazık ki her hangi bir bilimsel çalışma göremedim. Ancak uluslararası yayınlarının içinde Türkiye'de yayın yapan, adı İngilizce fakat yayınları Türkçe olan dergilerde, bazı Türkçe yayınları olduğunu saptadım. Bir derginin adının İngilizce olması ama yayınların Türkçe olması ve içinde sadece kendi ülkemiz vatandaşlarımızın yayınlarının yer alması, bu dergiyi uluslararası seçkin bir dergi yapar mı sorusunu da gündeme getirmektedir. Bu üzerinde düşünülmesi gereken ayrı bir konudur. Özgün eserleri ile örnek olabilecek kişilerin editörlük yapmasını beklemek, sanıyorum abartılı değildir. Şahsıma daha da ilginç gelen kerameti kendinden menkul bu gibi editörlerin dergisinde, bilim kurulunda yer alan, alanla ilgisiz öğretim üyelerinin varlığıdır. Daha da ilginci alanında uzmanlaşmış bir derneğin, böyle bir dergiyi nasıl olup da tanıttığıdır. Belki de bu dernek "ne dergiler var, dikkat edin" demek istemektedir. Okurlar ve makale yazarları olarak alanımızda yer alan dergi editörlerinin yapmış oldukları yayınları incelememiz, dergilerin kalitesi ve yayınlanacak yayınların kalitesi hakkında bizlere bilgi verebilecektir. Bu nedenledir ki bilim insanları için yayın yapılacak derginin seçimi ayrı bir önem taşımaktadır.

Hem ülkemizde hem de yurtdışında etik ilkeleri göz ardı edebilen yayıncılar ve editörler bulunabilmektedir. Ülkemizde bazı üniversiteler yağmacı (preditor) dergilerde yapılan yayınları 
kabul etmeyeceğini senato kararları ile beyan etmiştir (Hacettepe Üniversitesi 2020). Bu dergiler ve yayınevlerinde yayın yapılmaması amaciyla, küçük araştırma ve taramalar ile bu dergiler belirlenebilir. Yağmacı dergilerin listelerine, https:// beallslist.net/ ve https://beallslist.net/hijacked-journals/, https://predatoryjournals.com/journals/, http://www.library.hacettepe.edu.tr/sayfa/predatory bağlantılardan ulaşılabilir:

Burada yer alan dergilerin dışında listeye girmeye aday birçok derginin olduğu göz ardı edilmemelidir. Ülkemizde Energy Education Science and Technology adıyla yayınlanan ve bilim atıf endeksinde (SCI) yer alan bu dergi, etik olmayarak kendi kendine yaptığı atıflar ile dünyada etki faktörü en yüksek dergilerden biri olarak yer almiş ve tarihe geçmiştir (Al ve Soydal 2012). Bu ve benzeri dergilerde bilerek veya bilmeyerek yayın yapan ve doçentlik akademik yükseltme kriteri SCI veya SSCI'deki yayın yapma ölçütünü karşıladığını belirtip, doçent ve ardından profesör olan öğretim üyelerinin durumu da tartışmaya açıktır. Bu tür yağmacı dergilerde yayın yapmayarak, hatırı sayılır düzgün dergilerde yayın yapan akademisyenlerle temasta bulunulması ve hangi dergilerde nasıl yayın yapılması ile ilgili görüşlerinin alınması, araştırmacıların dikkat etmesi gereken hususlardan biridir.

\section{TARTIŞMA VE SONUÇ}

Bilimde ve her hangi bir araştırmanın temelinde, merak duygusunun yatması doğaldır. Bu merak araştırmacıyı, araştırmaya sevk etmektedir. Pandemi ve ardından gelen sürecin turizm alanında araştırma yapan bilim insanlarını harekete geçirmesin ardında, bu merak duygusunun yattığ 1 da bir gerçektir. Ancak bu merak duygusu bilimsel yöntem ve etik ile birleşmez ise fırsatçılığın doğurduğu kötü çalışmalarla karşılaşılması kuvvetle muhtemeldir. Araştırma öncesi iyi bir projesi önerisi hazırlanması, birçok sorunun önceden saptanmasını ve araştırmanın geliştirilmesini sağlayarak, araştırmanın daha sağlıklı yürütülmesini beraberinde getirecektir. Böylelikle çalışmanın ilgili kuram ve kuramlarla ilişkisi belirlenebilecek, buradan hareketle araştırma sorusu ve/veya hipotezler çok daha net olarak ortaya konulabilecektir. Yöntem ve yürütülecek analiz- lerin tasarımı başta yapılarak, proje önerisinin aslında düşünüldüğü gibi çalışmayı yavaşlatmadığı aksine çalışmayı sağlıklı bir ivmeye soktuğu görülebilecek, nihayetinde daha geçerli ve güvenilir çıktılar elde edilebilecektir. Bundan dolayıdır ki özellikle ekip çalışmalarında düzgün araştırma projesi önerisinin hazırlanması, araştırmaların daha nitelikli hale gelmesine yardımcı olabilir.

Bu çalışmada ele alınan sorun başlıklarının temelinde yatan unsurların dikkatli şekilde ele alınması gerekmektedir. Akademik yükseltmelerde ve teşviklerde yayın sayısının (nicelik), nitelikten daha önemli hale gelmesi, ilgili süreçlerde editör olmanın yarattığı kazanımlar ve buna bağlı olarak elektronik ortamda yayınlanan dergilerin çoğalması, makale üretimini artırmış ancak kaliteleri ile ilgili soruları da beraberinde getirmiştir. İyi niyetle düzenlemeye alınmış olan akademik yükseltme ve teşviklerin farklı sorunlar doğurduğu görülmekle birlikte, yaşanan bu sorunların ardında daha farklı faktörlerin olabileceği göz ardi edilmemelidir.

Araştırmacıların turizm ve rekreasyon alanını besleyen diğer bilim dallarındaki kuramsal gelişmeleri yakından izlemeleri ve eleştirel olarak değerlendirmeleri gerekmektedir. Varolan paradigmalara eleştiri getirebilmek için onların iyi bilinmesi gerekmektedir. Ülkemizde alan ile ilgili birçok lisansüstü program bulunmakta ve sayıları hızla artmaktadır. Açılan lisansüstü programlarda, nitelikli örnek yayınlar yapan yeterli sayıda öğretim üyesinin bulunmaması, bu çalışmada ele alınan sorunları körükleyen bir neden olabilir. Lisansüstü programların açılmasında, akademik teşvik ve yükseltmelerde daha sağlıklı ölçütlerin belirlenmesi, üretilecek yayınların kalitesinin artmasına yardımcı olabilecektir. Burada genel olarak alan ile ilgili yayınlarda yapilan temel sorunlar ele alınmıştır. Ancak buradaki sorunların tüm çalışmalar için geçerli olmadığının altı çizilmelidir. Alanımızda belli ekollerden gelen kişilerin, halen gayet güzel yayınlar yaptığını görmek sevindiricidir. Nitelikli yayınların artırılması yönelik neler yapılabileceği konusunda bir araştırma yapılması, alanımıza önemli bir katkı sağlayabilecektir. 


\section{KAYNAKÇA}

Al, U. ve Soydal, İ. (2012). Dergi Kendine Atıfının Etkisi: Energy Education Science and Technology Örneği, Türk Kütüphaneciliği Dergisi, 26 (4): 1-15.

Andersen, H. ve Hepburn, B. (2016). Scientific Method, The Stanford Encyclopedia of Philosophy, Edward N. Zalta (Editör), https://plato.stanford.edu/archives/sum2016/entries/scientific-method/, (Erişim tarihi: 22.07.2020).

Beall's List (2020). Beall's List of Potential Predatory Journals and Publishers, https://beallslist.net/, (Erişim tarihi: 22.07.2020).

Dergipark (2020). Dergiler, https://dergipark.org.tr/tr/ search?section=journal, (Erişim tarihi: 22.07.2020).

Hacettepe Üniversitesi Kütüphaneleri (2020). "Predatory" Dergiler Hakkında, http://www.library.hacettepe.edu.tr/ sayfalpredatory, (Erişim tarihi: 22.07.2020).

Hanel, P. H. ve Vione, K. C. (2016). Do Student Samples Provide an Accurate Estimate of the General Public?. PloS One, 11 (12). https://doi.org/10.1371/journal.pone.0168354, (Erişim tarihi: 22.07.2020).

OSFHOME (2020). The Place to Share Your Research, https:// osf.iol, (Erişim tarihi: 22.07.2020).

Özen, Ş. (2002). Türkiye'de Örgütler/Yönetim Araştırmalarında Törensel Görgülcülük Sorunu, Yönetim Araştırmaları Dergisi, 2 (2): 187-213.
Şener, S., Bahçeci, V., Doğru, H., Sel, Z. G., Ertaş, M., Songür, S. ve Tütüncü, Ö. (2016). Turizm Alanındaki Nitel Araştırmalarda Uygulanan Yöntem Ölçütlerinin Değerlendirilmesi, Anatolia: Turizm Araştırmaları Dergisi, 28 (1): $7-26$.

Stop Predatory Journals (2020). List of Predatory Journals, https://predatoryjournals.com/journals/, (Erişim tarihi: 22.07.2020).

Tütüncü, Ö. (2000). Turizm Sektöründe Araştırma Projesi Önerilerinde Temel Ölçütler ve Bir Proje Örneği, Dokuz Eylül Üniversitesi Sosyal Bilimler Enstitüsü Dergisi, 2 (2): 285-304. http://kisi.deu.edu.tr/userweb/ozkan. tutuncu/ArastirmaProjesi.pdf, (Erişim tarihi: 22.07.2020).

Yüksel, A. (2018). Aykırı: Araştırmalarda Yanılsamalar. Ankara: Detay Yayıncilik.

Yüksel, A. (2019). Turizm Akademisinde Yanılsamalar, Seyahat ve Otel İşletmeciliği Dergisi, 16 (2): 340-351, https:// dergipark.org.tr/tr/pub/soid/issue/47537/609112, (Erişim tarihi: 22.07.2020).

Özkan TÜTÜNCÜ, Prof. Dr., Dokuz Eylül Üniversitesi, Necat Hepkon Spor Bilimleri Fakültesi, Rekreasyon Bölümü, 35330 Seferihisar, Izmir.

E-posta: ozkan.tutuncu@deu.edu.tr

ORCID: 0000-0002-2482-0893 